Article

\title{
Steel Wire Mesh as a Thermally Resistant SERS Substrate
}

\author{
Tomasz Szymborski ${ }^{1,2}$ (D), Evelin Witkowska ${ }^{1}$, Krzysztof Niciński ${ }^{1}$, Zuzanna Majka $^{1}$ (D), \\ Tomasz Krehlik ${ }^{1}$, Tomiła Deskur ${ }^{1}$, Katarzyna Winkler ${ }^{1}$ and Agnieszka Kamińska ${ }^{1, *}$ (i) \\ 1 Institute of Physical Chemistry, Polish Academy of Sciences, Kasprzaka 44/52, Warsaw 01-224, Poland; \\ tszymborski@gmail.com (T.S.); evelinwitkowska@wp.pl (E.W.); krzysiekn92@gmail.com (K.N.); \\ zuza_majka@wp.pl (Z.M.); tomasz_krehlik@wp.pl (T.K.); tomila@interia.pl (T.D.); \\ kwinkler@ichf.edu.pl (K.W.) \\ 2 Soft Materials Laboratory, Institute of Materials, Ecole Polytechnique Fédérale de Lausanne, \\ 1015 Lausanne, Switzerland \\ * Correspondence: akamin@ichf.edu.pl; Tel.: +48-22-343-3112; Fax: +48-22-343-3333
}

Received: 4 July 2018; Accepted: 23 August 2018; Published: 26 August 2018

\begin{abstract}
In this paper, we present novel type of Surface-enhanced Raman spectroscopy (SERS) platform, based on stainless steel wire mesh (SSWM) covered with thin silver layer. The stainless steel wire mesh, typically used in chemical engineering industry, is a cheap and versatile substrate for SERS platforms. SSWM consists of multiple steel wires with diameter of tens of micrometers, which gives periodical structure and high stiffness. Moreover, stainless steel provides great resistance towards organic and inorganic solvents and provides excellent heat dissipation. It is worth mentioning that continuous irradiation of the laser beam over the SERS substrate can be a source of significant increase in the local temperature of metallic nanostructures, which can lead to thermal degradation or fragmentation of the adsorbed analyte. Decomposition or fragmentation of the analysed sample usually causea a significant decrease in the intensity of recorded SERS bands, which either leads to false SERS responses or enables the analysis of spectral data. To our knowledge, we have developed for the first time the thermally resistant SERS platform. This type of SERS substrate, termed Ag/SSWM, exhibit high sensitivity (Enhancement Factor $(\mathrm{EF})=10^{6}$ ) and reproducibility (Relative Standard Deviation (RSD) of $6.4 \%$ ) towards detection of $p$-mercaptobenzoic acid ( $p$-MBA). Besides, Ag/SSWM allows the specific detection and differentiation between Gram-positive and Gram-negative bacterial species: Escherichia coli and Bacillus subtilis in label-free and reproducible manner. The unique properties of designed substrate overcome the limitations associated with photoand thermal degradation of sensitive bacterial samples. Thus, a distinctive SERS analysis of all kinds of chemical and biological samples at high sensitivity and selectivity can be performed on the developed SERS-active substrate.
\end{abstract}

Keywords: Surface-enhanced Raman spectroscopy (SERS); wire mesh; steel mesh; SERS platform; Escherichia coli; Bacillus subtilis

\section{Introduction}

Surface-enhanced Raman spectroscopy (SERS) is nowadays one of the most powerful and reliable method in a wide range of applications including biochemistry [1], biomedical analysis [2], forensics, bio- and chemical hazards [3] and environmental monitoring [4,5].

In SERS effect, for molecules adsorbed onto metallic nanostructures, the Raman signal is amplified up to 14 orders of magnitude. Two mechanisms, an electromagnetic (EM) and a chemical (CT) are involved in SERS effect. An electromagnetic enhancement results from the amplification of incident 
light due to excitation of localized surface plasmon resonance (LSPR) of the metal surface. It was found that the morphology and dielectric environment of the plasmonic nanostructures plays a crucial role in the EM mechanism. The chemical enhancement process involves the charge-transfer occurring between the metal surface and adsorbed molecules, which can enhance the transition polarizability of adsorbates [6]. Typically, the electromagnetic enhancement can reach factors $10^{3}-10^{11}$, whilst the chemical enhancement contributes additional factor up to $10^{3}[7,8]$. As a result of these mechanisms, SERS ensures the ultratrace detection of analytes down to single molecules [9]. Besides ultrasensitvity and fingerprint specificity, SERS technique offers nondestructive, label-free, and fast detection of analytes under a wide range of conditions (excitation wavelength and power of the laser, temperature, pressure, presence of water).

These features lead to an increase of the practical applications of SERS technique especially in biological materials studies, starting from single macromolecules and ending with whole cells (for example, microorganisms) [10-14]. The SERS spectra of biomolecules carries the information about their structure. This technique also offers the quantitative and qualitative studies with the possibility of multiplexed detection of analytes in complex fluids such as blood, cerebrospinal fluid or urine.

However, the practical implementation of SERS technique in a clinical setting is hindered by the difficulties in generation of a model SERS-active nanostructures. Such SERS substrate should reveal homogenous and high enhancement factor $(\mathrm{EF})$ across the surface, as well as chemical and physical stability. Additionally, the fabrication method of SERS substrates should be as cheap as possible and provide large-scale production. The commonly used SERS substrates are based on the nanostructured noble metals e.g. $\mathrm{Ag}, \mathrm{Au}, \mathrm{Cu}$, however the most frequently used metal is silver as it is quite cheap in comparison with gold and provides very high SERS enhancement (much higher than for copper). Interestingly, SPR (surface plasmon resonance) application of Ag is not only important from the point of view of SERS studies, but also covers other technologically important fields such as photocatalysis $[15,16]$.

Today, a variety of techniques have been applied to fabricate SERS nanostructures, such as electrochemical methods [17], nanosphere lithography [18], electron-beam lithography [19], nanoimprinting lithography [20], vapour layer deposition [21], colloidal suspension [22], and many other strategies.

Lately, our research group has developed several types of novel nanomaterials, which can be used in a wide range of biomedical studies [23-28]. In recent research works we have investigated the membrane-based SERS-platforms [26,29], where polymer mats covered with gold nanostructures enable filtration of bacteria from fluids (for example, blood plasm), their immobilization on the filter surface, and enhancement of Raman signal. This solution overcomes the problem of transferring bacteria from filter to the SERS platform and potential contamination of the sample, and, at the same time, enables detection of very low concentration of bacteria. Nowadays, there are many different types of materials which are used to produce SERS-active substrates, e.g. ceramics [30,31], silver nanorods [32], mesoporous silica [33], ultrafiltration membrane [34], filter paper [35,36] or metal nanocrystals [37]. Particularly interesting are the polymer-based manufacturing techniques, due to the low cost and ease of production. However, polymer substrates cannot meet the demands of high stiffness of the substrate and high heat transfer (i.e. heat dissipation). Therefore, we have expanded our research by developing the thermally resistant SERS platforms. Continuous irradiation of the laser beam over the SERS substrate can be a source of significant increase in the local temperature of metallic nanostructures, what is a critical issue in SERS measurements of heat-sensitive materials [38,39]. Thermal degradation or fragmentation of the analyte is a vital problem during examination of heat-sensitive materials like DNA, proteins, polymers or lipid bilayers [40]. Moreover, molecules that are adsorbed to the metal surface (e.g. thiols at gold) can desorb at a temperature of $60-100{ }^{\circ} \mathrm{C}$ [40]. Decomposition or fragmentation of the analyte often leads to broadening and reduction of the intensity of observed spectral bands, and as a result, to misinterpretation of analytical data [41,42]. 
Another issue is connected with possible degradation of the polymer in contact with water (biodegradable polymers like poly(L-lactide acid) (PLLA) or polylactid acid (PLA)) or in contact with organic solvents. Biological samples involve water-based samples (blood, urine, cerebrospinal fluid), therefore used polymers should not be biodegradable in water environment, especially when the filtration process is long.

To conclude, there is a strong need for cheap, versatile, durable, stable SERS-platform which can easily dissipate heat thus can be used with high power lasers. Such platform should, preferably, be resistant to water and other organic and inorganic solvents. In this paper, we present a new type of SERS platforms based on woven wire mesh made of stainless steel (referred here as a stainless-steel wire mesh, SSWM). There are four types of woven meshes: plain weave, twilled weave, plain Dutch weave, and twilled Dutch weave, all having periodic structure which makes them excellent base for SERS platform. They are used as a filtration media in chemical industry $[43,44]$ due to their ability to withstand large pressures, high heat resistance, small aperture and reusability. We used twilled Dutch SSWM as a base for our SERS-platform: the SSWM was cleaned and sputtered with 50 nm thick layer of silver which ensured the high amplification of the Raman signal. The dense mesh structure also provided good deposition of the analyte on the surface.

The developed SERS platforms, named Ag/SSWM, show very high surface-enhancement factor $\left(1 \times 10^{6}\right)$, high stability (up to one month under ambient conditions), high reproducibility, and high thermal resistance to laser irradiation. These Ag/SSWM substrates demonstrated a great potential in sensitive and reproducible SERS-based detection of typical analyte like $p$-MBA, as well as whole microorganisms, that is, Escherichia coli and Bacillus subtilis.

\section{Materials and Methods}

\subsection{Chemicals and Materials}

P-mercaptobenzoic acid ( $p$-MBA) and phosphate-buffered saline (PBS) packs (10 mM, $\mathrm{pH}=7.2$ ) were obtained from Sigma-Aldrich (Dorset, UK) and used without further purification. Water (resistivity over $18 \mathrm{M} \Omega$ ), purified using a Milli-Q plus 185 system was used throughout the process. Stainless steel wire mesh was obtained with Anping County Huijin Wire Mesh Co., Ltd., Anping, China. Each type of mesh wire was purchased in quantity of $1 \mathrm{~m}^{2}$ and deposited rolled in room temperature prior to use.

\subsection{Instrumentation}

\subsubsection{Raman and SERS Spectroscopy}

Measurements were carried out with a Renishaw inVia Raman system (Wotton-under-Edge, Gloucestershire, UK) equipped with a $785 \mathrm{~nm}$ diode laser (Wotton-under-Edge, Gloucestershire, UK)). The light from the laser was passed through a line filter and focused on a sample mounted on an $X-Y-Z$ translation stage with a $50 \times$ microscope objective, Numerical Aperture (NA) $=0.75$. The beam diameter was approximately $5 \mu \mathrm{m}$. The laser power at the sample was $5 \mathrm{~mW}$ or less. The microscope was equipped with 1200 grooves per mm grating, cut-off optical filters, and a $1024 \times 256$ pixel Peltier-cooled RenCam CCD detector (Wotton-under-Edge, Gloucestershire, UK), which allowed registering the Stokes part of Raman spectra with $5-6 \mathrm{~cm}^{-1}$ spectral resolution and $2 \mathrm{~cm}^{-1}$ wavenumber accuracy. The experiments were performed at ambient conditions using a back-scattering geometry. The time required for completing a single SERS spectrum was 4 seconds for $p$-MBA and 40 seconds for bacteria.

The obtained spectra were processed with an OPUS software (Bruker Optic GmbH 2012 version, Ettlingen, Germany). The spectra were smoothed with Savitsky-Golay filter, the background was removed using baseline correction, and then the spectra were normalized using a so-called Min-Max normalization. 


\subsubsection{Scanning Electron Microscopy (SEM)}

Observations were performed under high vacuum using the FEI Nova NanoSEM 450 (Hillsboro, OR, USA). The accelerating voltage was in rage from 2 to $10 \mathrm{kV}$. The SSWM samples with bacteria cells were observed without any additional layer of gold.

\subsection{Preparation of the SERS Platform and Sample Measurement.}

General scheme of preparation of SERS-active platform for Raman measurements is shown in Figure 1. Wire mesh sample $(40 \times 40 \mathrm{~mm})$ was cut with scissors from big sheet $(100 \mathrm{~cm} \times 100 \mathrm{~cm})$ and placed in baker filled with acetone. In the first step the sample was sonicated for $10 \mathrm{~min}$ in ultrasonic bath at a temperature of $50^{\circ} \mathrm{C}$ (Figure 1a). Then the acetone was exchanged and the step was repeated. After $10 \mathrm{~min}$ the baker was filled with isopropyl alcohol and the sample was sonicated for $10 \mathrm{~min}$ at a temperature of $50{ }^{\circ} \mathrm{C}$ (Figure 1b). Then the sample was sonicated for $10 \mathrm{~min}$ in distilled water (Millipore) at ambient temperature (Figure 1c). Cleaned wire-mesh was then dried for $30 \mathrm{~min}$ at $50^{\circ} \mathrm{C}$ (Figure 1d) and placed in a sterile Petri dish or immediately placed in a Physical Vapour Deposition (PVD) device and sputtered with a 50 nm layer of silver (Figure 1e). The prepared SERS platform is ready for use.

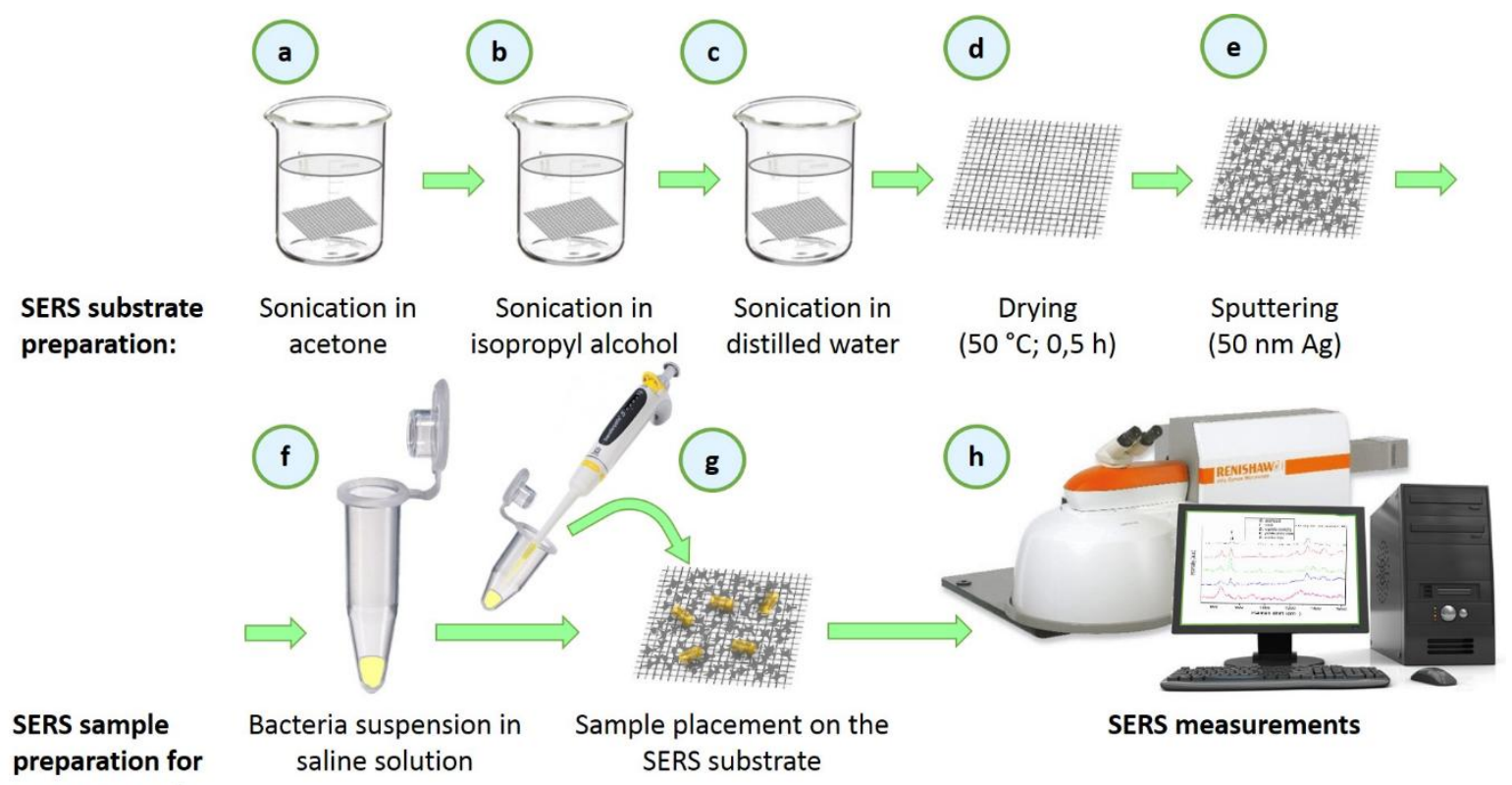

Figure 1. The scheme showing the preparation of SERS substrate, sample deposition and SERS measurement. The main steps involve cleaning (a-c), drying (d), sputtering of thin layer of silver (e), deposition of bacteria on SSWM platform $(\mathbf{f}, \mathbf{g})$, and SERS measurement $(\mathbf{h})$.

To perform our measurements, we placed three bacterial colonies in micro-tubes filled with $500 \mu \mathrm{L}$ of saline solution (Figure 1f), which was vortexed and then placed on platform with pipette (Figure 1g). Then the SERS platform with deposited bacteria was placed under microscope and subjected to measurements (Figure 1h).

\subsection{Bacteria Culture and Its Preparation for SERS Measurements}

\subsubsection{Bacteria Culture and SERS Sample Preparation}

E. coli and B. subtilis were obtained from the Department of Applied Microbiology, Institute of Microbiology, University of Warsaw, Warsaw, Poland. In the case of each species, bacteria were 
streaked on the Petri dishes with LB agar (Luria-Bertani broth agar) and incubated at $37^{\circ} \mathrm{C}$ for $24 \mathrm{~h}$. Next, three single bacterial colonies were suspended in $500 \mu \mathrm{L}$ of saline solution $(0.9 \% \mathrm{NaCl}$ solution) and centrifuged for $5 \mathrm{~min}$ at $1070 \times \mathrm{g}$. Then, the supernatant was decanted and the pellet of bacterial cells was re-suspended in $500 \mu \mathrm{L}$ of saline solution. The obtained concentration of bacterial cells was $5 \times 10^{9} \mathrm{~mL}^{-1}$. This process was repeated three times in order to obtain clean sample of microbial cells without any additional contamination form cell culture medium. After discarding the supernatant in the last step of centrifugation, bacteria cells were suspended in $20 \mu \mathrm{L}$ of saline solution, transferred via pipette and placed onto SSWM substrate (Figure 1f,g). The sample was left to dry for 5 min and then the SERS measurements (Figure 1h) were conducted.

\subsubsection{Procedure of Silver Sputtering}

To sputter a layer of silver we used the PVD equipment (EM MED020, Leica, Heerbrugg, Switzerland). The silver target was obtained from Mennica Metale Szlachetne, Warsaw, Poland. The target diameter was $54 \mathrm{~mm}$, thickness was $0.5 \mathrm{~mm}$, and silver purity was $4 \mathrm{~N}$. The vacuum during the silver sputtering was on the level of $10^{-2} \mathrm{mbar}$, whereas the sputtering current was $25 \mathrm{~mA}$. After the deposition process the samples were placed into a sterile Petri dish.

Six different thicknesses of silver layer on the SSWM substrates, i.e., 5, 20, 35, 50, 70 and $100 \mathrm{~nm}$, were tested to find optimal conditions for SERS enhancement.

\section{Results and Discussion}

\subsection{Characterization of Wire Mesh and Its Surface}

In our experiments, we used five different wire meshes (see Table 1), made of stainless steel 316 (austenitic chromium-nickel stainless steel containing molybdenum). Addition of molybdenum increases general corrosion resistance, improves resistance to pitting from chloride ion solutions, and provides increased strength at elevated temperatures. The corrosion resistance of 316 steel is improved, particularly against acid sulphates, alkaline chlorides, and sulfuric, hydrochloric, acetic, formic and tartaric acids. What is important, the thermal conductivity of steel 316 is $16.3 \mathrm{~W} \cdot \mathrm{m}^{-1} \cdot \mathrm{K}^{-1}$, whereas polymer, for example, PLA thermal conductivity is ca. $0.19 \mathrm{~W} \cdot \mathrm{m}^{-1} \cdot \mathrm{K}^{-1}$ [45]. That large thermal conductivity of stainless steel is what makes it superior base material for SERS platform.

Table 1. Types and parameters of wire meshes used in experiments. All wire meshes are made of stainless steel 316. Mesh refers to the number of warp and weft wires per inch.

\begin{tabular}{ccccc}
\hline $\begin{array}{c}\text { Number of } \\
\text { Sample }\end{array}$ & Mesh & $\begin{array}{c}\text { Warp Diameter } \\
{[\mu \mathrm{m}]}\end{array}$ & $\begin{array}{c}\text { Weft Diameter } \\
{[\mu \mathrm{m}]}\end{array}$ & Type of Weave \\
\hline I & $80 \times 800$ & 120 & 70 & twill Dutch \\
II & $200 \times 1400$ & 50 & 40 & twill Dutch \\
III & $250 \times 2000$ & 45 & 27 & twill Dutch \\
IV & $325 \times 2300$ & 35 & 25 & twill Dutch \\
V & $400 \times 3100$ & 30 & 17 & twill Dutch \\
\hline
\end{tabular}

Figure 2 presents general organization of the wires in twill Dutch weave fabric, while Figure 3 presents SEM pictures of all wires meshes (see Table 1) at three different magnifications. As can be seen, the twill Dutch type is extremely dense and tightly woven fabric. Twill refers to the structure of the fabric: over two and under two weaving wires with respect to the warp wires (warp are wires running lengthwise of the cloth, whereas weft are wires running across the cloth). The term Dutch means that the weft wires have smaller diameter than the warp wires (see Table 1 for details). The structure of twill Dutch weave is presented in Figure 3, whereas the schematic illustration of the weft and warp wires structure is presented in Figure S1. 


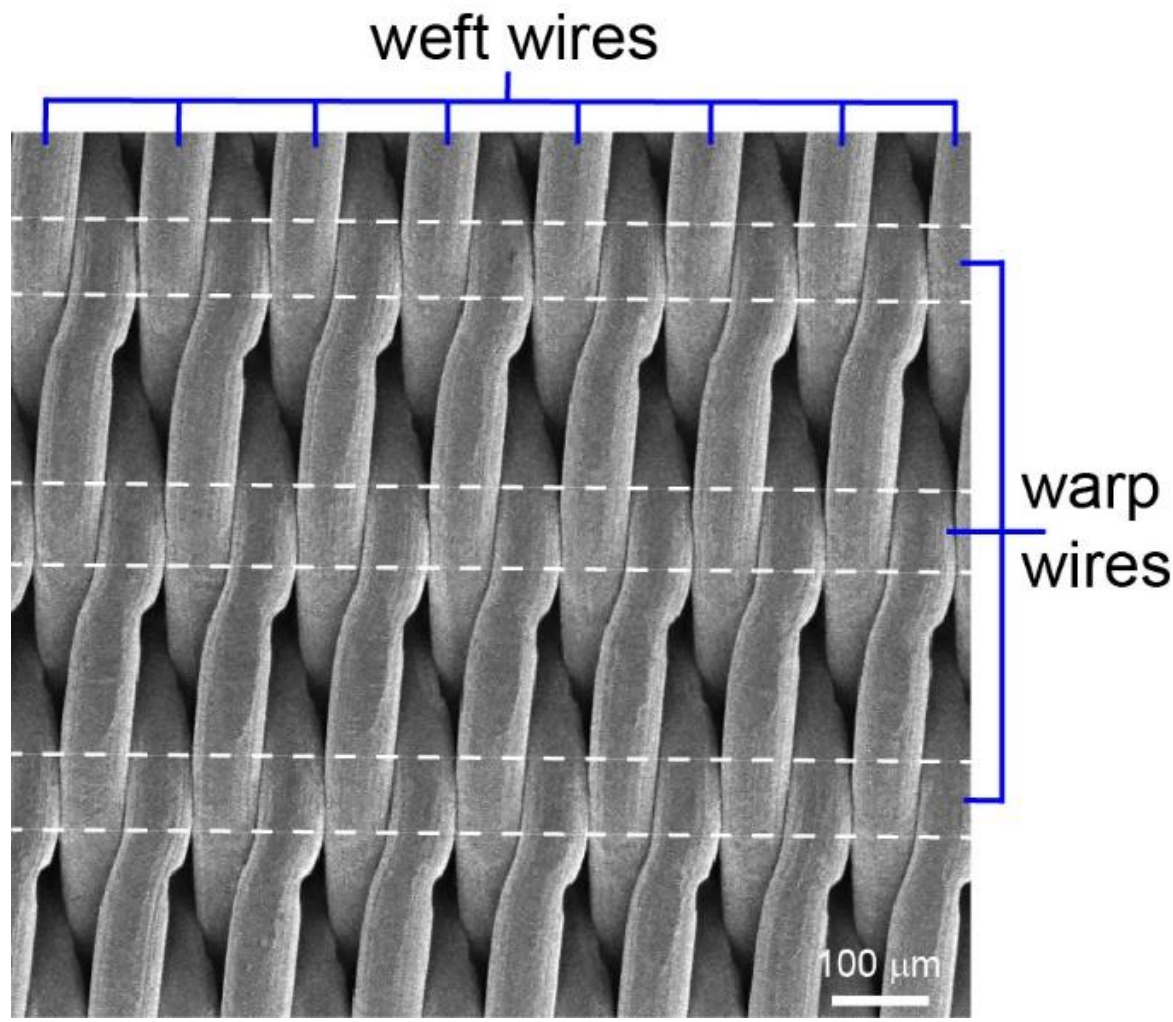

Figure 2. Twill Dutch weave is a densly woven fabric made of 316 stainless steel. It consists of two types of wires: warp (with a higher diameter) and weft (with a smaller diameter). The presented picture is a SEM of $80 \times 800$ wire mesh.

Twill Dutch weave enables the weft wires to be woven more densely. Therefore, much smaller aperture sizes can be achieved. The term mesh $($ e.g. $80 \times 800)$ refers to the number of warp $(80)$ and weft (800) wires per inch.

Figure 3 shows the representative SEM images of five wire meshes (I-V), for three different magnifications. All samples were sputtered with $50 \mathrm{~nm}$ of silver via PVD method as described before. This method provides a homogeneous coverage of the SSWM surface with the layer of silver.

SEM image at high magnification exhibits homogeneously placed silver nanostructures. The image analysis has been performed to quantify their size distribution. Representative image and its histogram for sample I $(80 \times 800)$ is presented in Figure 4, while the histograms for all studied samples are depicted in Figure S2. It can be noticed that for all samples the avarage size of the silver nanostructures on the surface of the wires is below $45 \mathrm{~nm}$, while the median is below $40 \mathrm{~nm}$. These parameters are optimal for the LSPR. 

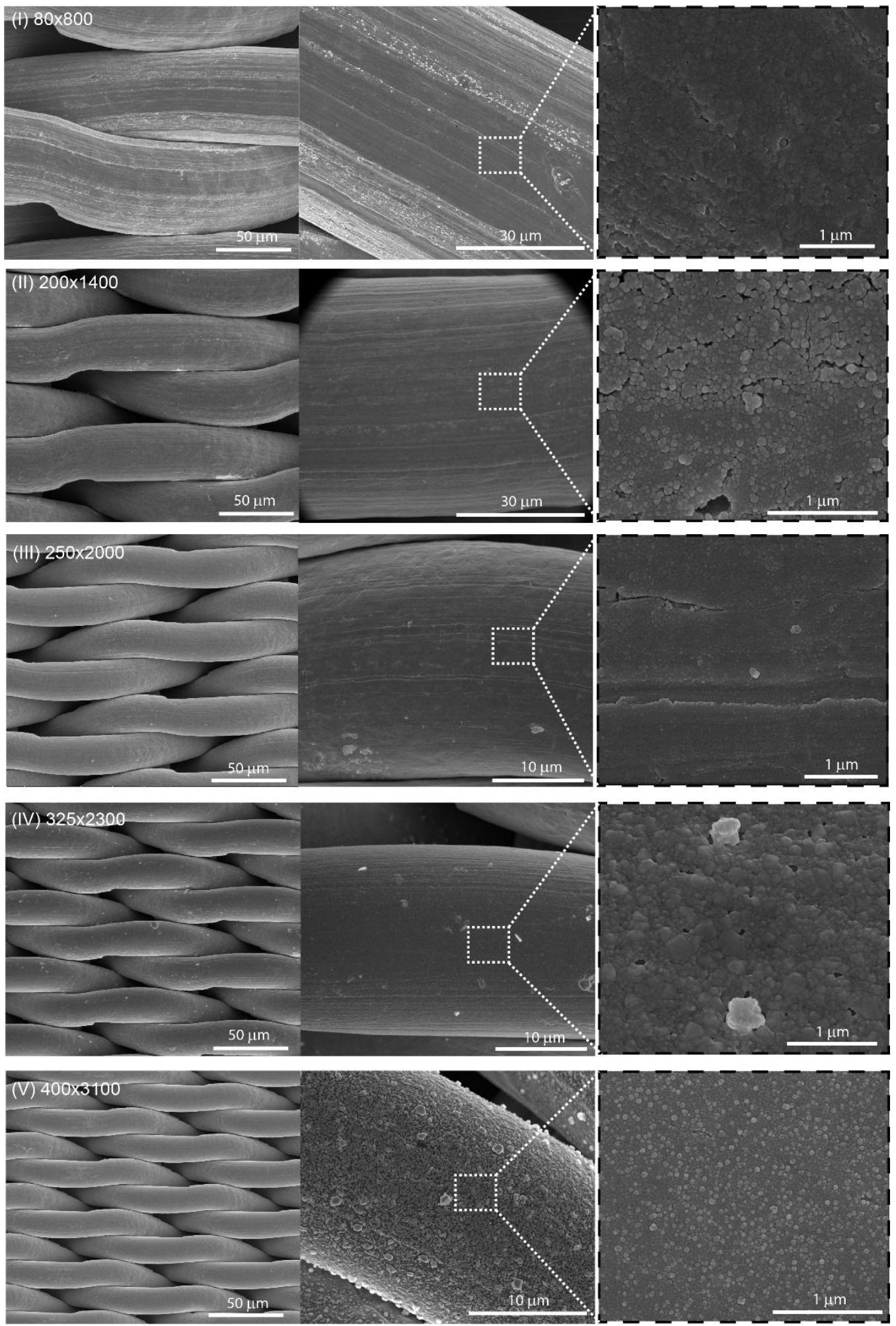

Figure 3. SEM images of SERS-active platforms (sputtered with $50 \mathrm{~nm}$ layer of silver via PVD technique) at three different magnifications. Parameters of the wire meshes are described in Table 1. 

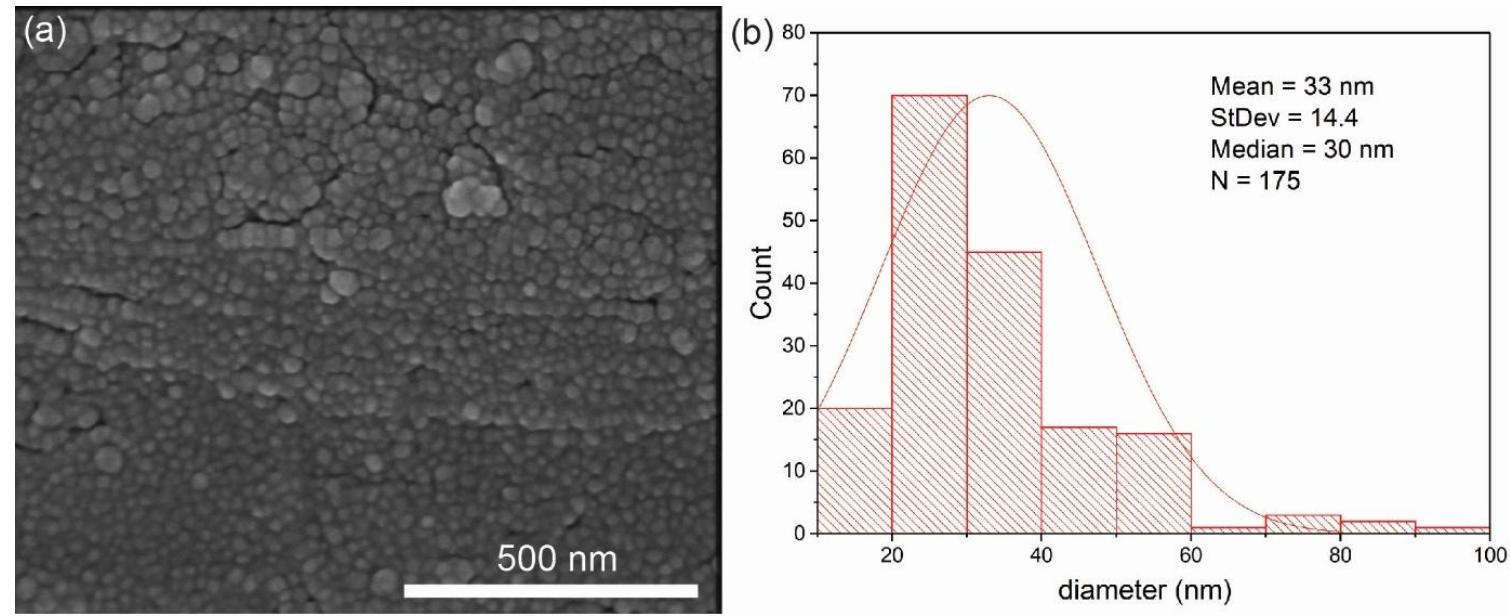

Figure 4. The surface of $80 \times 800$ (I) wire mesh covered with $50 \mathrm{~nm}$ layer of silver (a) and histogram of the size of the Ag nanostructures on the surface (b). The avarage size of these nanostructures is $33.0 \mathrm{~nm} \pm 14.4 \mathrm{~nm}$.

\subsection{SERS Properties of $A g / S S W M$ Substrate}

The SERS efficiency (sensitivity, selectivity, and reproducibility) is strongly correlated with the morphology of the SERS-active nanostructures. The $p$-MBA was used as a standard probe compound in order to prove the SERS properties of fabricated Ag/SSWM substrates. In this study, five different wire mesh surfaces (Figure 3) have been investigated in the terms of their spectroscopic properties.

In the first step, the SERS sensitivity of the Ag/SSWM substrates was examined and described by the enhancement factors (EF) for $p$-MBA. The $p$-MBA molecules bind through its thiol groups to the top silver layer of SERS-active surface and thus allow to record the intense SERS responses. Moreover, the intensities of $p$-MBA SERS features depend on the plasmonic properties of the SERS substrate and are not affected by the possible electronic resonance mechanism.

The Ag/SSWM substrate was kept in $1.0 \mathrm{~mL}$ of $1.0 \times 10^{-6} \mathrm{M} p$-MBA ethanol solution for $3 \mathrm{~h}$ and then washed with deionized water. The Raman bands at 708, 796, 1075, 1176, 1474 and $1588 \mathrm{~cm}^{-1}$ are characteristic for $p$-MBA [46]. The surface enhancement factors for $p$-MBA have been calculated according to the standard equation:

$$
E F=\frac{I_{S E R S} N_{N R}}{I_{N R} N_{S E R S}}
$$

where $N_{\mathrm{NR}}$ stands for the number of molecules sampled by normal Raman measurements, whereas $N_{\text {SERS }}$ describes the number of molecules irradiated in SERS technique. $I_{\text {NR }}$ and $I_{\text {SERS }}$ were measured at $1075 \mathrm{~cm}^{-1}$ and correspond to the normal Raman scattering intensity of $p$-MBA in the bulk and the SERS intensity of $p$-MBA adsorbed to metallic nanostructures.

The laser spot area and the effective illuminated volume are fundamental parameters for the estimation of EF. The effective illuminated volume has been calculated using a formula recommended by Renishaw:

$$
V=3.21 \times \lambda^{3}(f / D)
$$

where $f$ is the microscope objective focal length and $\mathrm{D}$ represents the effective laser beam diameter at the objective back aperture. For our setup, $V=2012 \approx 2 \times 10^{3} \mu \mathrm{m}^{3}$. The laser beam diameter, defined as twice the radius of a circle encompassing the area with $86 \%$ of the total power was about $2.5 \mu \mathrm{m}$. It should be highlighted that approximately the same values were achieved from the experimentally obtained laser spot image and from the theoretical formula $(4 \lambda f / \pi \mathrm{D})$. Assuming the volume in a shape of a cylinder with the diameter of $5 \mu \mathrm{m}$ leads to the effective height of $100 \mu \mathrm{m}$. This value was confirmed by recording Raman spectra of Si while varying the distance from the focal plane. 
The SERS samples were prepared by immersing the substrate in $1 \mathrm{~mL}$ of $1.0 \times 10^{-6} \mathrm{M}$ solution of $p$-MBA. The number of molecules in the solution was $6.02 \times 10^{14}\left(6.02 \times 10^{23}\right.$ molecules $/ \mathrm{mol}$ $\times 1.0 \times 10^{-3} \mathrm{~L} \times 1.0 \times 10^{-6} \mathrm{~mol} / \mathrm{L}=6.02 \times 10^{14}$ molecules $)$. The surface area irradiated by the laser beam $\left(2.5 \mu \mathrm{m}\right.$ in diameter) was $19.6 \mu \mathrm{m}^{2}\left(3.14 \times 1.25 \mu \mathrm{m}^{2}=4.9 \mu \mathrm{m}^{2}\right)$. The surface of our samples was $10 \mathrm{~mm}^{2}$. Therefore, about $2.3 \times 10^{8}$ molecules were present in the laser beam spot. The normal Raman spectrum was observed for a cell filled with a pure $p$-MBA $\left(154.19 \mathrm{~g} \cdot \mathrm{mol}^{-1}\right.$; density of $1.06 \mathrm{~g} \cdot \mathrm{cm}^{-3}$ ). The effective illuminated volume for our setup is $2 \times 10^{3} \mu \mathrm{m}^{3}$. Under these conditions, $N_{\mathrm{NR}}=8.1 \times 10^{12}$ molecules were irradiated by the laser. From these data of the relative intensity and the number of molecules sampled from the regular Raman and SERS measurements, the enhancement factors for all studied SERS surfaces have been calculated.

Figure 5 depicts the SERS spectra of $p$-MBA molecules adsorbed from $10^{-6} \mathrm{M}$ ethanol solution onto five studied surfaces (Figure 3). The enhancement factors for each surface (named from I to V) were calculated using equation (1) and are presented in Table 2 . The highest enhancement factor has been found for the surface I (Table 2), which indicate that its morphology matches to the optimal size of nanostructures $(20-40 \mathrm{~nm})$ for the efficient LSPR.

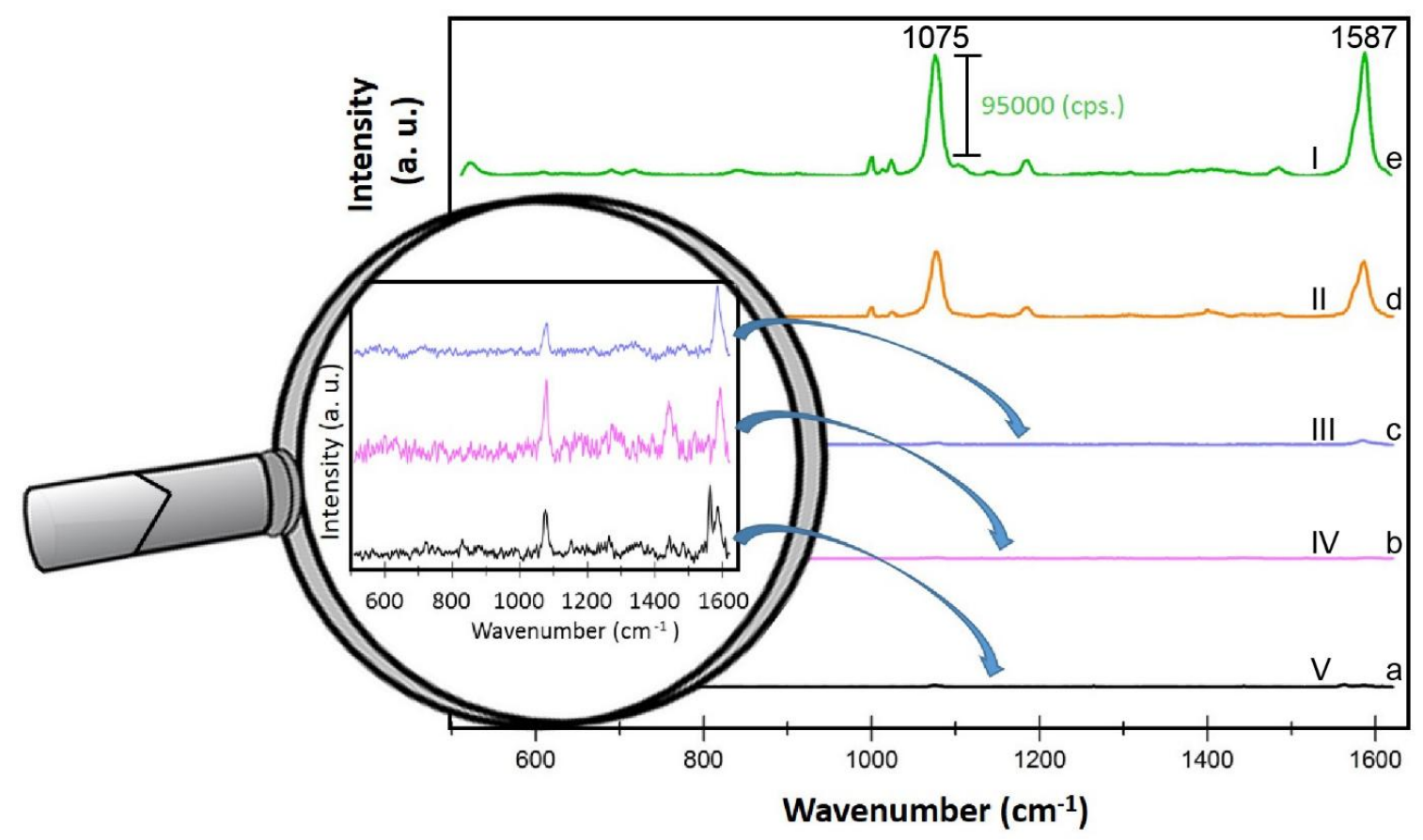

Figure 5. SERS spectra of $p$-MBA recorded from five different SERS substrates (a-e) with varying morphology of wire mesh (according to parameters described in Table 1). Experimental conditions: $5 \mathrm{~mW}$ of $785 \mathrm{~nm}$ excitation, $2 \times 5$ seconds acquisition time. The image in magnifier presents the close view of the region with marker band at $1075 \mathrm{~cm}^{-1}$ for SSWM surfaces showing low EF. Each SERS spectrum was averaged from twenty measurements in different places of SERS surface.

Table 2. The EF factors for five different Ag/SSWM substrates (Table 1).

\begin{tabular}{ccc}
\hline Number & Mesh & Enhancement Factor (EF) \\
\hline I & $80 \times 800$ & $4.2 \times 10^{6}$ \\
II & $200 \times 1400$ & $1.3 \times 10^{5}$ \\
III & $250 \times 2000$ & $1.0 \times 10^{3}$ \\
IV & $325 \times 2300$ & $1.2 \times 10^{3}$ \\
V & $400 \times 3100$ & $0.8 \times 10^{3}$ \\
\hline
\end{tabular}


As was mentioned above, in order to acquire SERS activity of the SSWMs platforms, they were covered with silver layer in PVD process. The deposited silver film thickness affects the size and the density of formed silver nanostructures [47]. Figure 6 shows the dependence between the intensity of the marker bands of $p$-MBA at $1075 \mathrm{~cm}^{-1}$ and the thickness of the deposited silver film. As can be seen the $5 \mathrm{~nm}$ layer of silver was insufficient to achieve the reasonable SERS responses for $p$-MBA. The intensity of $p$-MBA SERS spectrum increased significantly when the thickness of silver layer increased from 20 to $50 \mathrm{~nm}$ (Figure 6).

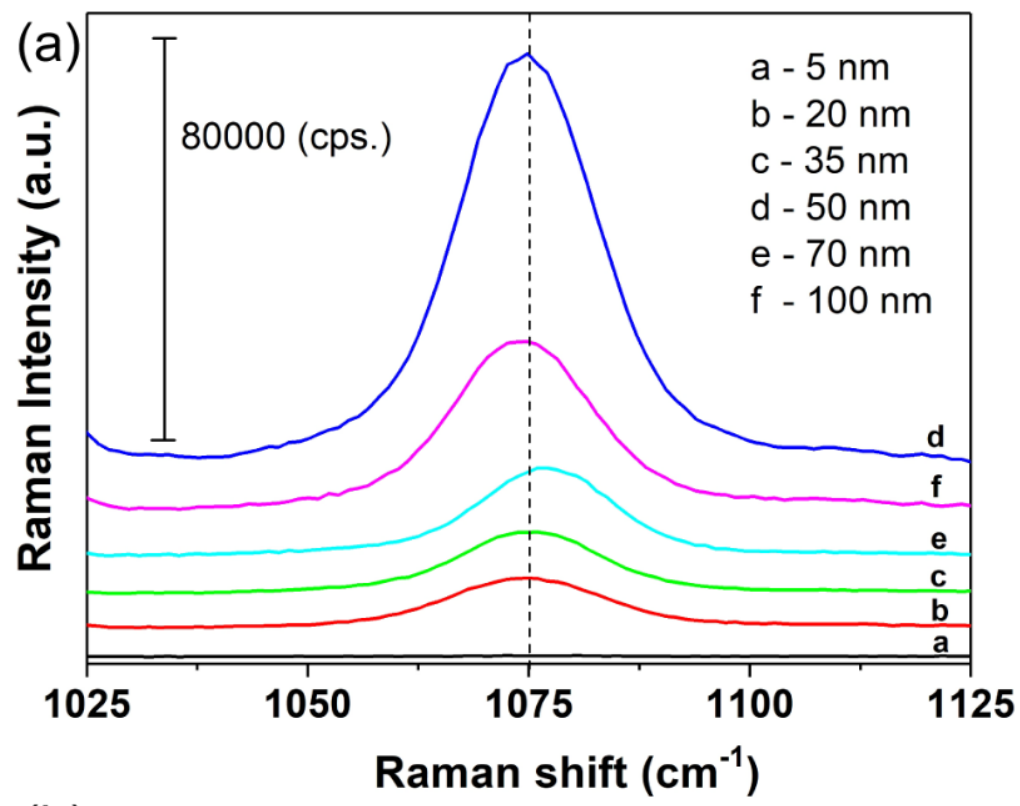

(b)

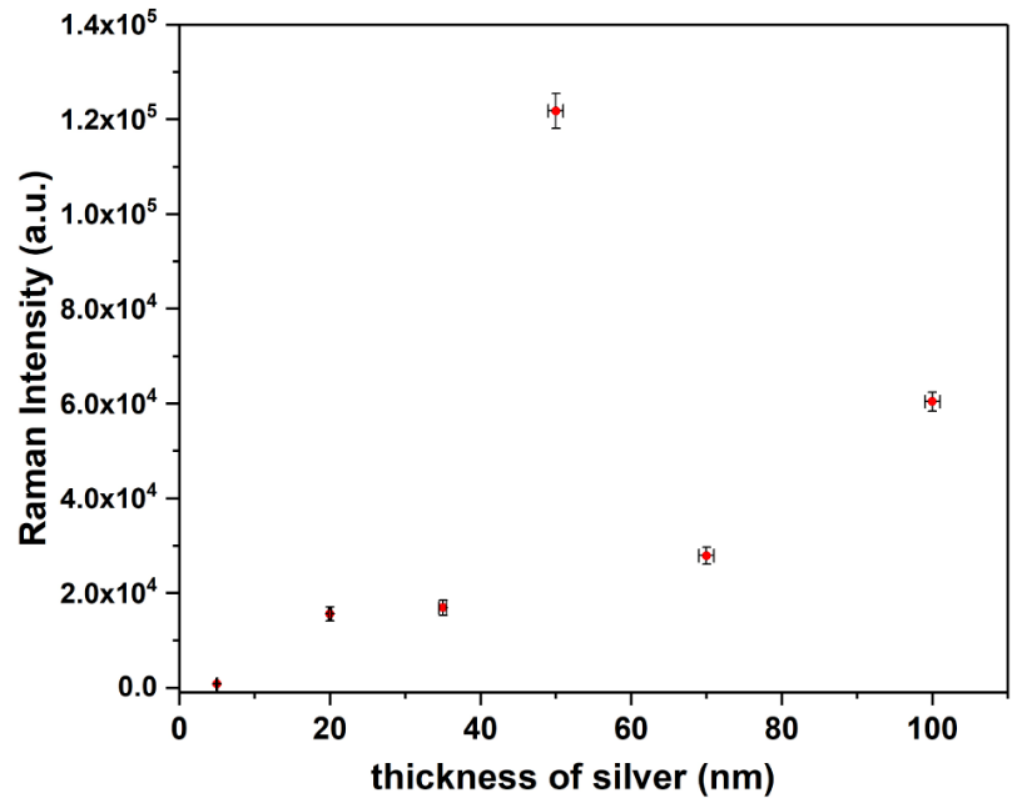

Figure 6. The intensity of SERS band at $1075 \mathrm{~cm}^{-1}$ with varying Ag metal thickness $(5 \mathrm{~nm}, 20 \mathrm{~nm}$, $35 \mathrm{~nm}, 50 \mathrm{~nm}, 70 \mathrm{~nm}$ and $100 \mathrm{~nm}$ ) for Type I surface: mesh $80 \times 800$ : (a) Raman spectra, (b) numerical values of Raman intensity. The error bars in the Figure $6 \mathrm{~b}$ shows standard deviation of both thickness of the silver layer and Raman signal intensity. 
The maximum intensity of the marker bands of $p$-MBA has been recorded for $50 \mathrm{~nm}$ thickness of the deposited layers of silver. Further increase in the amount of silver leads to decrease in intensity of SERS bands.

It should be highlighted that, despite the numerous theoretical and experimental works, the nature of the Raman signal enhancement in SERS technique is still not obvious. However, as mentioned above, two enhancement mechanism (long-range electromagnetic effect (EM) and short-range charge-transfer effect) are involved in SERS phenomenon. It has been found that the dominating electromagnetic enhancement in SERS is caused by surface plasmon resonances on the substrate. This is an example of amplification of incident light intensity by excitation of surface plasmons. Briefly, the factors which determine the absorbance and the bandwidth of the plasmon resonance include the size, shape, and density of the metal nanostructures. In this case the morphology and microstructure of the Ag nanofilms onto SSWM also play a crucial role in EM effect of SERS enhancement.

These results indicate, that the $50 \mathrm{~nm}$ thickness of the Ag metal film results in an optimal size (average size of the objects is $33.0 \mathrm{~nm} \pm 14.4 \mathrm{~nm}$ ) and distribution of silver nanostructures for a plasmon resonance effect for $785 \mathrm{~nm}$ laser line. The distribution of the nanostructures determines the formation of 'hot spots' on the SERS substrate. It is possible that mentioned factors (suitable size of silver nanostructures, number and distribution of 'hot spots') make significant contribution to the observed SERS enhancement.

The thicker layers of silver (70 and $100 \mathrm{~nm}$ ) results in decrease of SSWM roughness and thus lead to the loss of optimal condition for LSPR [48].

To summarize: (i) the stainless steel wire Type I, mesh $80 \times 800$ (Table 1, Figure 3) and (ii) $50 \mathrm{~nm}$ thickness of the Ag metal film results in obtaining the most efficient SERS-active platform. This type of substrate has been applied for further analysis of bacterial cells. In all experiments the $785 \mathrm{~nm}$ excitation wavelength was applied, as it is the compromise between the signal intensity and background fluorescence [49], especially during the measurements of biological samples. Additionally, we have also checked that the SERS intensity of $1075 \mathrm{~cm}^{-1}$ marker band of $p$-MBA increases ranging from 532 to $785 \mathrm{~nm}$ (see Table S1 in Supplementary Materials). This behavior has been recently discussed in literature [50]. The reflectance spectra of enhancing substrates are used to the detection of far-field electromagnetic (EM) enhancement mechanisms, while the near-field modes could be responsible of the strong long-wavelength resonances in the range of 700-850 nm [50], and explain these experimental results. The dark plasmons (example of non-radiating modes) detected in nanogaps and/or aggregated nanostructures [51] are indicated as potential origins of such huge Raman signal enhancements [52].

It should be highlighted that the developed Type I SERS-active surface show excellent sensitivities for $p$-MBA, also at concentrations as low as $10^{-9} \mathrm{M}$. Figure S3 depicts the SERS spectra of $p$-MBA adsorbed onto Type I SERS surface at different concentrations (a) $10^{-3} \mathrm{M}$, (b) $10^{-6} \mathrm{M}$, and (c) $10^{-9} \mathrm{M}$ in ethanol. It is clear that a steady decrease in SERS intensity of the $p$-MBA SERS band is observed with decreasing $p$-MBA concentration. However, even at $10^{-9} \mathrm{M}$ concentration the intensity of the marker band at $1075 \mathrm{~cm}^{-1}$ is above 1000 cps for $2 \times 2$ seconds of acquisition time, which still enables the SERS sensing.

\subsection{Applications of Ag/SSWM SERS Substrate: Differentiation Between Gram-Positive and Gram-Negative Bacteria Species}

In order to present the bioanalytical potential of developed SERS surface the SERS spectra of two different bacteria species: E. coli (Gram-negative) and B. subtilis (Gram-positive) were recorded. As can be seen in the Figure 7, the obtained SERS spectra of both bacteria species show major peaks at around $650,725,960,1000,1100,1330,1375,1460$ and $1590 \mathrm{~cm}^{-1}$ and less intense bands at around 565, 780, 850, $1030,1275 \mathrm{~cm}^{-1}$. The peak at around $565 \mathrm{~cm}^{-1}$ may originate from $C-O-C$ ring deformation [53] or $C-C$ skeletal vibration [54], while the one at $650 \mathrm{~cm}^{-1}$ - from $C-S$ stretching in methionine [55] and/or $C-C$ twisting mode of tyrosine [56]. The most intense band, located at $725 \mathrm{~cm}^{-1}$, can be assigned to 
adenine derivatives [57]. The peak at $780 \mathrm{~cm}^{-1}$ comes probably from ring breathing modes in the DNA/RNA bases (uracil, thymine and cytosine) [58] and the one at $850 \mathrm{~cm}^{-1}$-from asymmetric $O-P-O$ stretching and/or tyrosine [59]. The bands at $\sim 960$ and $1000 \mathrm{~cm}^{-1}$ originate probably from $\mathrm{C}-\mathrm{N}$ stretching [60] and from phenylalanine [61], respectively. The phosphodioxy group $\left(\mathrm{PO}_{2}^{-}\right)$from nucleic acids can be observed in the spectrum in a form of the peak at $1092 \mathrm{~cm}^{-1}$ [62], while the amide III and $\mathrm{CH}_{2}$ wagging vibrations from glycine backbone and proline sidechains can be detected as the band at $1275 \mathrm{~cm}^{-1}$ [63]. Finally, the bands at around 1333, 1375, 1460 and $1590 \mathrm{~cm}^{-1}$ can be assigned to adenine [64], $\mathrm{COO}$ stretching [65], $\mathrm{CH}_{2}$ bending [53] and $\mathrm{C}=\mathrm{C}$ olefinic stretching [60], respectively.

Although the presented in Figure 7 spectra show a lot of similar bands, there still can be noticed some peaks due to which the obtained spectra can be easily distinguished. This refers to the bands at $620,1127,1205,1242$ and $1402 \mathrm{~cm}^{-1}$ which can be seen only in the case of $E$. coli spectrum, and to bands located at 1140 and $1535 \mathrm{~cm}^{-1}$, which are detected only in B. subtilis spectrum. Moreover, some SERS signals, which are present in the spectra of both bacteria species, are more intense for $E$. coli, for example, 1001 and $1333 \mathrm{~cm}^{-1}$, and some for B. subtilis, for example, 650 and $\sim 1375 \mathrm{~cm}^{-1}$. Based on these differences it can be concluded that Ag/SSWM SERS substrates can be applied for successful detection and identification of bacteria.

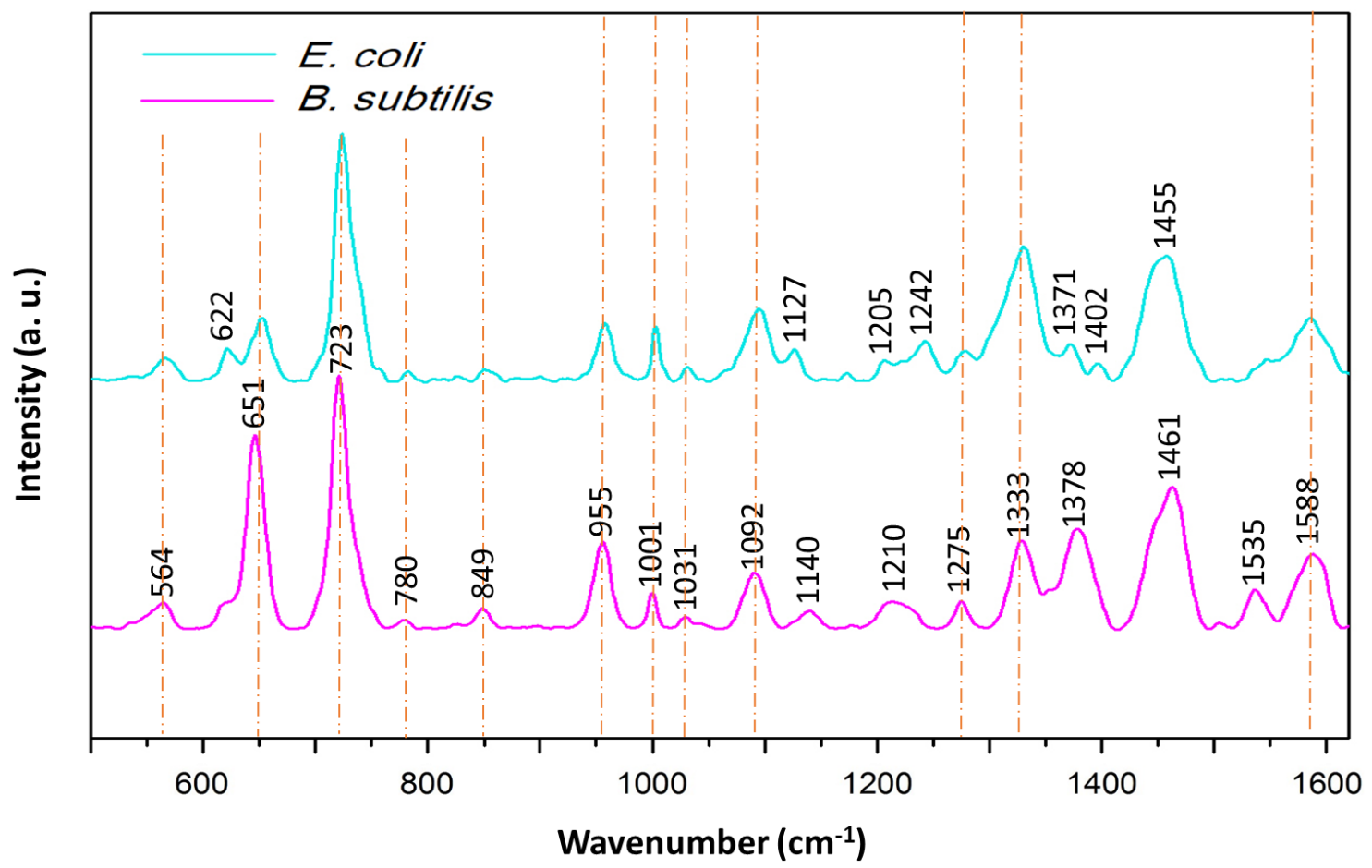

Figure 7. Average SERS spectra E. coli (turquoise) and B. subtilis (pink) recorded on Ag/SSWM (mesh $80 \times 800$ covered with $50 \mathrm{~nm}$ layer of Ag) SERS platforms. For all spectra, excitation wavelength was at $785 \mathrm{~nm}$, laser power was $5 \mathrm{~mW}$, and acquisition time was 30 seconds. Each SERS spectrum of examined bacteria was averaged from 30 measurements in different places across the SERS surface using mapping mode.

Additionally, the presence of bacteria cells onto the Ag-coated SSWM have been confirmed by SEM images (see Figure 8). The images show the E. coli cells, approximately $2-2.5 \mu \mathrm{m}$ in diameter, scattered uniformly over the steel wire. Figure $8 \mathrm{~b}$ reveals that bacteria are arranged in lines. The reason of such arrangement is connected with the structure of the stainless wire, which is produced via wire drawing. This process produces unevenness on the wire surface, which are parallel to the wire axis. These irregularities (scratches) are in the scale of single micrometres and perfectly match the diameter of bacteria cells. 

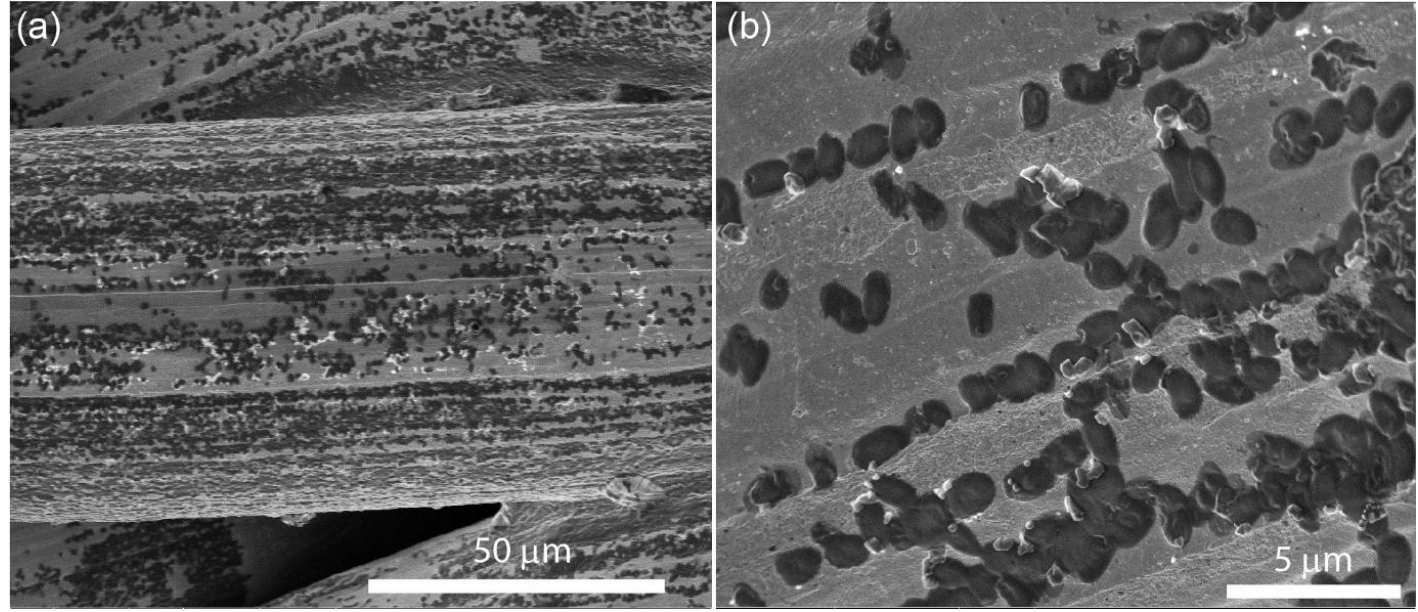

Figure 8. SEM images of E. coli placed onto Ag/SSWM surface and collected at (a) lower and (b) higher magnification. The bacteria are arranged in lines due to irregularities of wire surface.

\subsection{RepRoducibility and Thermal Resistance of the SERS Substrate}

To estimate the reproducibility of prepared Ag/SSWM substrates, the relative standard deviation (RSD) was calculated for SERS spectra of $p$-MBA, B. subtilis, and E. coli. Figures 9 and S4 presents obtained results for particular Type I substrate. The calculated RSD values equal $6.4 \%, 11 \%$, and $9.5 \%$, respectively. All these data indicate that the developed SERS substrates can be applied in biomedical and analytical studies.
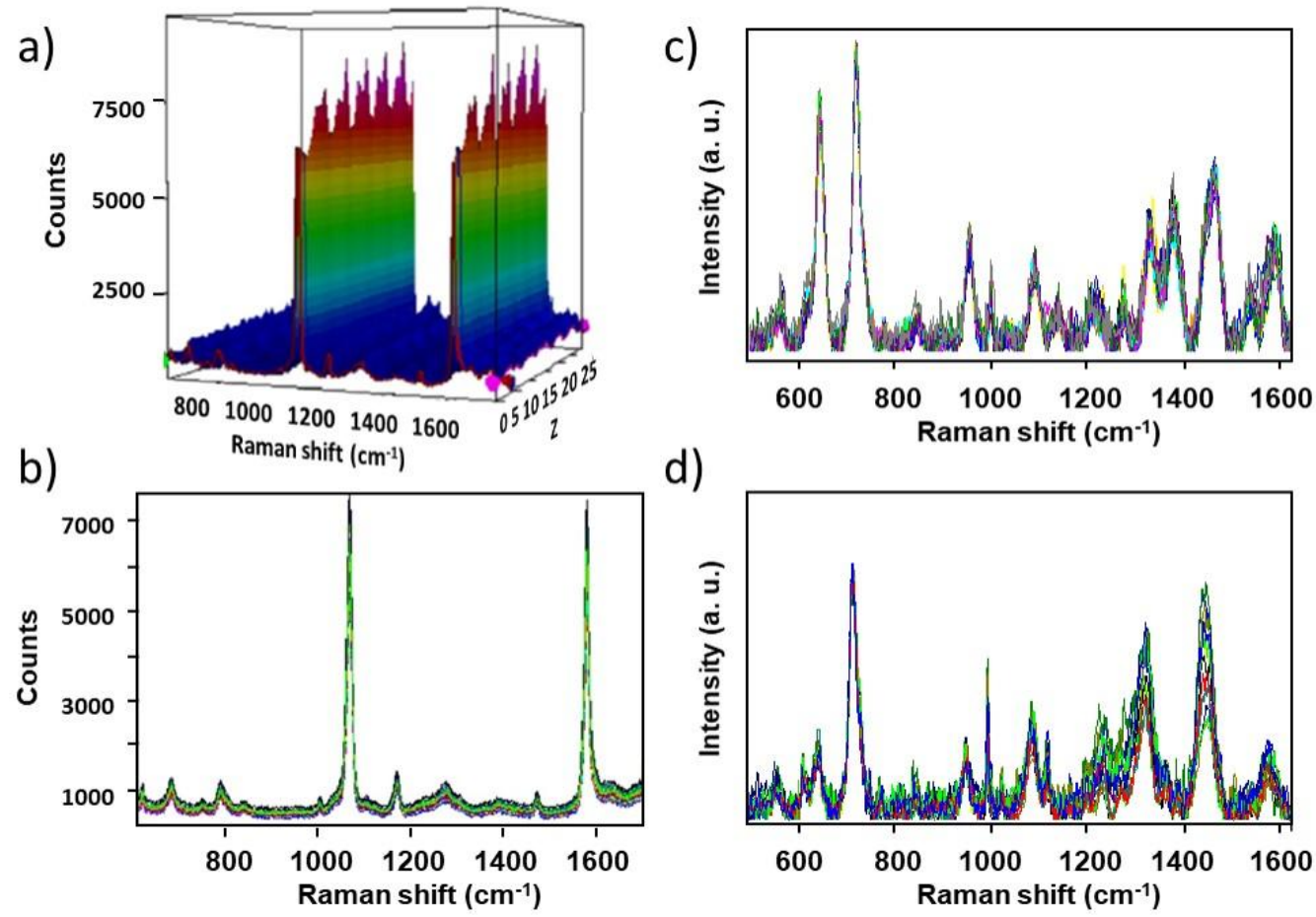

Figure 9. The representative SERS spectra of $(\mathbf{a}, \mathbf{b})$ p-MBA of concentration of $10^{-6} \mathrm{M},(\mathbf{c})$ B. subtilis, and (d) E. coli recorded from 30 different spots on the SERS surface (Type I) using mapping mode. The spectra were collected over a distance of $1 \mathrm{~mm}$ with $10 \mu \mathrm{m}$ steps (30 spectra are shown). Each point in the map was recorded using $5 \mathrm{~mW}$ of $785 \mathrm{~nm}$ excitation. 
The application of SERS technique within biology and medicine is a rapidly expanding field of science since SERS can provide chemical, biochemical, and structural information through the generation of fingerprint spectra or spectral imaging. This method of analysis does not require a complex sample preparation, and can also be applied without a complicated labelling strategy, and does not suffer from interference from water. However, besides the long list of advantages there are some limitations associated with SERS techniques. The wavelength of the exciting laser and its power onto the irradiated sample are the key factors that determine the spectral resolution. The spatial resolution is defined by the optic of microscope objective and the wavelength of the laser. In biological studies the NIR (near-infrared) lasers at $785 \mathrm{~nm}$ and $830 \mathrm{~nm}$, which have relatively low photon energy and allow the reduction of fluorescence contribution in Raman spectrum, are commonly used. The power of laser illuminating the sample depends on the laser spot size and the magnification of the microscope. His in turn results in the intensity of scattered light. The biological samples are usually low-scattering materials and are very sensitive to the radiation damage or local thermal decomposition.

The burning or photo-degradation of biological samples, especially over prolonged period of excitation at too high laser power often results in appearance of the additional band in the recorded SERS spectrum at ca. $1500 \mathrm{~cm}^{-1}$ (Figure S5). The presence of the mentioned peak is usually associated with the formation of amorphous carbon. On the other hand, the reduced laser power during measurements results in very poor spectral quality and generate an invaluable information.

To detect such week intensities of Raman scattered light and to obtain high-quality spectral features the special thermal resistant SERS-active substrates-which enable effective distribution and/or heat dissipation during intensive laser illumination-have been applied. These thermal resistant SERS-active platforms can be used not only for detection/identification of biological specimens, but also for examination of variety of thermally degradable analytes or materials.

To demonstrate the thermal capability of developed SERS-active surfaces the same volume of E. coli in saline solution has been deposited onto two different kinds of the SERS substrates based on: (1) poly-L-lactic acid (PLLA) and (2) SSWM surfaces. The SERS data have been recorded at various intensities of excited laser power (see Figure 10).

The results demonstrate that $14.5 \mathrm{~mW}$ power of laser degrades E. coli on PLLA polymer mat/Ag, whereas bacteria on SSWM/Ag exhibit excellent spectra. Such result can be explained by very good thermal conductance of stainless steel (nearly 100 times higher than for PLLA). Therefore, no significant increase in temperature at the measurement spot is observed in the case of SSWM. In practice, the laser power below $5 \mathrm{~mW}$ is used for SERS measurements of biological samples.

To summarize, the results presented in this work show an excellent sensitivity, reproducibility, and thermal stability of obtained SERS substrates (Type I), which can be successfully used during the detection of biological samples. 


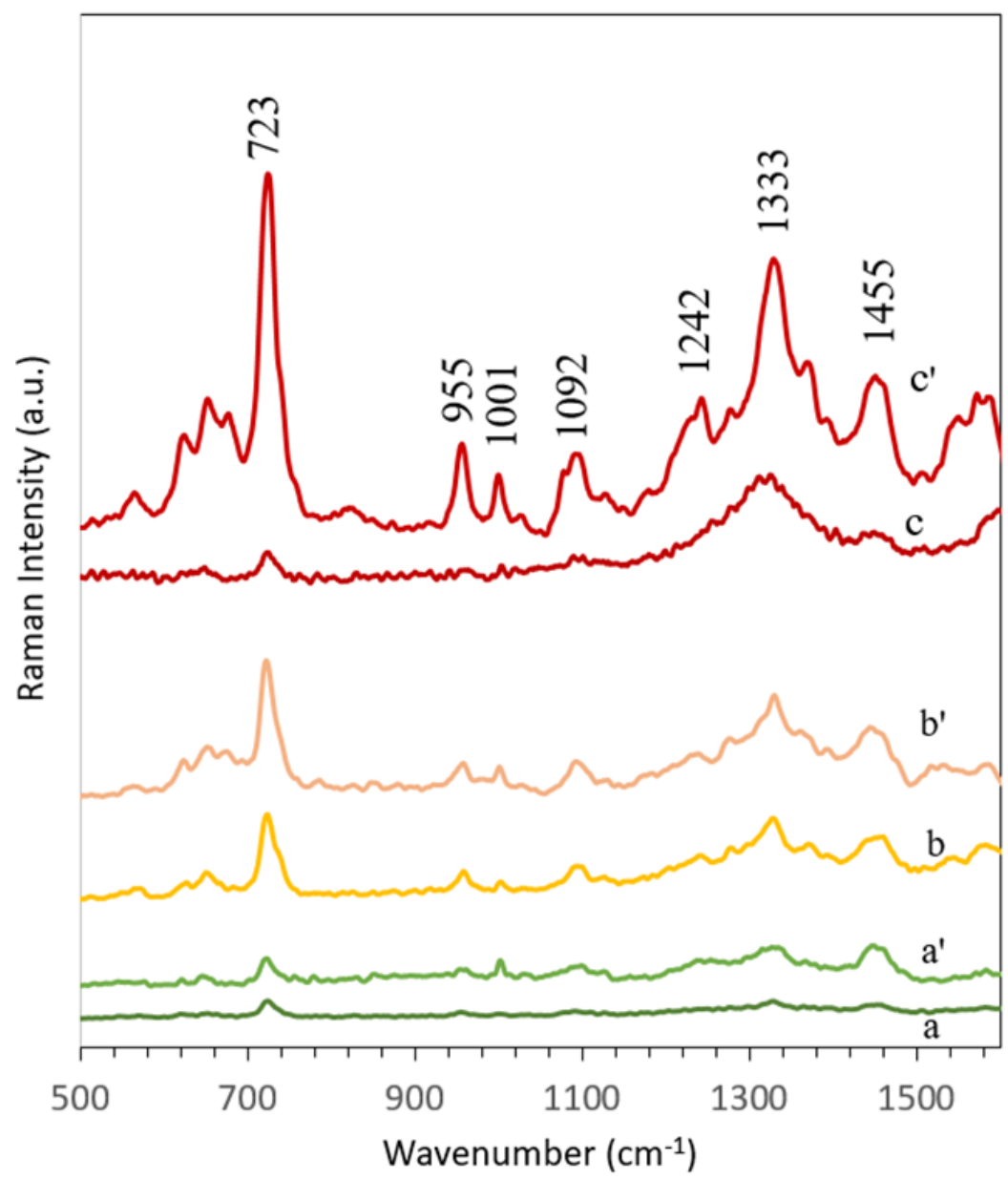

Figure 10. The SERS spectra of E. coli recorded on two different SERS substrates based on: polymer mat-PLLA $(a, b, c)$ and the stainless steel wire mesh - SSWM $\left(a^{\prime}, b^{\prime}, c^{\prime}\right)$ recorded with different powers of $785 \mathrm{~nm}$ excitation wavelength: (a, $\left.\mathrm{a}^{\prime}\right) 0.6 \mathrm{~mW},\left(\mathrm{~b}, \mathrm{~b}^{\prime}\right) 1.3 \mathrm{~mW}$, and (c, c') $14.5 \mathrm{~mW}$.

\section{Conclusions}

The present study demonstrates a new type of SERS platform based on woven wire mesh made of stainless steel (SSWM). The influence of the diameter of wires, their morphology and metal thickness on SERS efficiency was investigated and the optimal fabrication process parameters were established. In this paper, for the first time, we present the SERS substrate that exhibits excellent heat dissipation, which is a critical factor in SERS measurements of thermally sensitive samples. Our substrate enables generation of the high spectral resolution data even for very poorly scattering biological materials via safe adjustment of laser intensity to higher values. This approach overcomes the limitations associated with photo-and thermal degradation of sensitive materials, improves the spectral intensities of week Raman scatterers, and thus extends the rage of valuable SERS applications. In addition, the developed SERS substrate enables the detection and differentiation of Gram-positive and Gram-negative bacterial species in label-free manner, based on their high-quality spectral features.

Supplementary Materials: The following are available online at http:/ /www.mdpi.com/2079-4991/8/9/663/s1.

Author Contributions: Conceptualization, T.S. and A.K., Data curation, E.W., Investigation, Z.M. and T.K and K.W., Methodology, K.N Validation, T.D., Writing original draft, A.K.

Funding: Foundation for Polish Science under grant Team-Tech/2017-4/23.

Conflicts of Interest: The authors declare no conflict of interest. 


\section{References}

1. Wilson, C.G.; Graham, D.; McBride, E.; Girkin, J.M.; Stokes, R.J.; Smith, W.E. Surface-Enhanced Raman Scattering Spectroscopy as a Sensitive and Selective Technique for the Detection of Folic Acid in Water and Human Serum. Appl. Spectrosc. 2008, 62, 371-376.

2. Kneipp, K.; Kneipp, H.; Kartha, V.B.; Manoharan, R.; Deinum, G.; Itzkan, I.; Dasari, R.R.; Feld, M.S. Detection and identification of a single DNA base molecule using surface-enhanced Raman scattering (SERS). Phys. Rev. E 1998, 57, R6281-R6284. [CrossRef]

3. Rodger, C.; Dent, G.; Watkinson, J.; Smith, W.E. Surface-Enhanced Resonance Raman Scattering and Near-Infrared Fourier Transform Raman Scattering as in Situ Probes of Ink Jet Dyes Printed on Paper. Appl. Spectrosc. 2000, 54, 1567-1576. [CrossRef]

4. Faulds, K.; Smith, W.E.; Graham, D.; Lacey, R.J. Assessment of silver and gold substrates for the detection of amphetamine sulfate by surface enhanced Raman scattering (SERS). Analyst 2002, 127, 282-286. [CrossRef] [PubMed]

5. Koglin, E.; Séquaris, J.-M. Surface Enhanced Raman Scattering of Biomolecules; Springer: Berlin/Heidelberg, Germany, 1986; pp. 1-57.

6. Campion, A.; Kambhampati, P. Surface-enhanced Raman scattering. Chem. Soc. Rev. 1998, 27, 241. [CrossRef]

7. Stiles, P.L.; Dieringer, J.A.; Shah, N.C.; Van Duyne, R.P. Surface-Enhanced Raman Spectroscopy. Annu. Rev. Anal. Chem. 2008, 1, 601-626. [CrossRef] [PubMed]

8. Camden, J.P.; Dieringer, J.A.; Wang, Y.; Masiello, D.J.; Marks, L.D.; Schatz, G.C.; Van Duyne, R.P. Probing the Structure of Single-Molecule Surface-Enhanced Raman Scattering Hot Spots. J. Am. Chem. Soc. 2008, 130, 12616-12617. [CrossRef] [PubMed]

9. Le Ru, E.C.; Etchegoin, P.G. Single-Molecule Surface-Enhanced Raman Spectroscopy. Annu. Rev. Phys. Chem. 2012, 63, 65-87. [CrossRef] [PubMed]

10. Sivanesan, A.; Witkowska, E.; Adamkiewicz, W.; Dziewit, Ł.; Kamińska, A.; Waluk, J. Nanostructured silver-gold bimetallic SERS substrates for selective identification of bacteria in human blood. Analyst 2014, 139, 1037. [CrossRef] [PubMed]

11. Alexander, T.A.; Le, D.M. Characterization of a commercialized SERS-active substrate and its application to the identification of intact Bacillus endospores. Appl. Opt. 2007, 46, 3878-3890. [CrossRef] [PubMed]

12. Bonifacio, A.; Millo, D.; Gooijer, C.; Boegschoten, R.; van der Zwan, G. Linearly moving low-volume spectroelectrochemical cell for microliter-scale surface-enhanced resonance Raman spectroscopy of heme proteins. Anal. Chem. 2004, 76, 1529-1531. [CrossRef] [PubMed]

13. Nabiev, I.R.; Morjani, H.; Manfait, M. Selective analysis of antitumor drug interaction with living cancer cells as probed by surface-enhanced Raman spectroscopy. Eur. Biophys. J. 1991, 19, 311-316. [CrossRef] [PubMed]

14. Morjani, H.; Riou, J.F.; Nabiev, I.; Lavelle, F.; Manfait, M. Molecular and cellular interactions between intoplicine, DNA, and topoisomerase II studied by surface-enhanced Raman scattering spectroscopy. Cancer Res. 1993, 53, 4784-4790. [PubMed]

15. Chen, K.-H.; Pu, Y.-C.; Chang, K.-D.; Liang, Y.-F.; Liu, C.-M.; Yeh, J.-W.; Shih, H.-C.; Hsu, Y.-J. Ag-Nanoparticle-Decorated $\mathrm{SiO}_{2}$ Nanospheres Exhibiting Remarkable Plasmon-Mediated Photocatalytic Properties. J. Phys. Chem. C 2012, 116, 19039-19045. [CrossRef]

16. Chen, W.-T.; Hsu, Y.-J.; Kamat, P.V. Realizing Visible Photoactivity of Metal Nanoparticles: Excited-State Behavior and Electron-Transfer Properties of Silver ( $\left.\mathrm{Ag}_{8}\right)$ Clusters. J. Phys. Chem. Lett. 2012, 3, $2493-2499$. [CrossRef] [PubMed]

17. Wang, H.-H.; Liu, C.-Y.; Wu, S.-B.; Liu, N.-W.; Peng, C.-Y.; Chan, T.-H.; Hsu, C.-F.; Wang, J.-K.; Wang, Y.-L. Highly Raman-Enhancing Substrates Based on Silver Nanoparticle Arrays with Tunable Sub-10nm Gaps. Adv. Mater. 2006, 18, 491-495. [CrossRef]

18. Dick, L.A.; McFarland, A.D.; Haynes, C.L.; Van Duyne, R.P. Metal film over nanosphere (MFON) electrodes for surface-enhanced Raman spectroscopy (SERS): Improvements in surface nanostructure stability and suppression of irreversible loss. J. Phys. Chem. B 2001, 106, 853-860. [CrossRef]

19. Fromm, D.P.; Sundaramurthy, A.; Kinkhabwala, A.; Schuck, P.J.; Kino, G.S.; Moerner, W.E. Exploring the chemical enhancement for surface-enhanced Raman scattering with Au bowtie nanoantennas. J. Chem. Phys. 2006, 124, 61101. [CrossRef] [PubMed] 
20. Alvarez-Puebla, R.; Cui, B.; Bravo-Vasquez, J.-P.; Veres, T. Nanoimprinted SERS-Active Substrates with Tunable Surface Plasmon Resonances. J. Phys. Chem. C 2007, 111, 6720-6723. [CrossRef]

21. Semin, D.J.; Rowlen, K.L. Influence of Vapor Deposition Parameters on SERS Active Ag Film Morphology and Optical Properties. Anal. Chem 1994, 66, 4324-4331. [CrossRef]

22. Faulds, K.; Smith, W.E.; Graham, D. Evaluation of Surface-Enhanced Resonance Raman Scattering for Quantitative DNA Analysis. Anal. Chem. 2004, 76, 412-417. [CrossRef] [PubMed]

23. Kamińska, A.; Witkowska, E.; Kowalska, A.; Skoczyńska, A.; Ronkiewicz, P.; Szymborski, T.; Waluk, J. Rapid detection and identification of bacterial meningitis pathogens in: Ex vivo clinical samples by SERS method and principal component analysis. Anal. Methods 2016, 8. [CrossRef]

24. Kamińska, A.; Sprynskyy, M.; Winkler, K.; Szymborski, T. Ultrasensitive SERS immunoassay based on diatom biosilica for detection of interleukins in blood plasma. Anal. Bioanal. Chem. 2017, 409, 6337-6347. [CrossRef] [PubMed]

25. Kamińska, A.; Winkler, K.; Kowalska, A.; Witkowska, E.; Szymborski, T.; Janeczek, A.; Waluk, J. SERS-based Immunoassay in a Microfluidic System for the Multiplexed Recognition of Interleukins from Blood Plasma: Towards Picogram Detection. Sci. Rep. 2017, 7. [CrossRef] [PubMed]

26. Witkowska, E.; Szymborski, T.; Kamińska, A.; Waluk, J. Polymer mat prepared via Forcespinning ${ }^{\mathrm{TM}}$ as a SERS platform for immobilization and detection of bacteria from blood plasma. Mater. Sci. Eng. C 2017, 71. [CrossRef] [PubMed]

27. Kamińska, A.; Szymborski, T.; Jaroch, T.; Zmysłowski, A.; Szterk, A. Gold-capped silicon for ultrasensitive SERS-biosensing: Towards human biofluids analysis. Mater. Sci. Eng. C 2018, 84, 208-217. [CrossRef] [PubMed]

28. Kamińska, A.; Witkowska, E.; Winkler, K.; Dzięcielewski, I.; Weyher, J.L.; Waluk, J. Detection of Hepatitis B virus antigen from human blood: SERS immunoassay in a microfluidic system. Biosens. Bioelectron. 2015, 66, 461-467. [CrossRef] [PubMed]

29. Szymborski, T.; Witkowska, E.; Adamkiewicz, W.; Waluk, J.; Kamińska, A. Electrospun polymer mat as a SERS platform for the immobilization and detection of bacteria from fluids. Analyst 2014, 139. [CrossRef] [PubMed]

30. Mosier-Boss, P.A.; Sorensen, K.C.; George, R.D.; Sims, P.C.; O'braztsova, A. SERS substrates fabricated using ceramic filters for the detection of bacteria: Eliminating the citrate interference. Spectrochim. Acta Part A Mol. Biomol. Spectrosc. 2017, 180, 161-167. [CrossRef] [PubMed]

31. Mosier-Boss, P.A.; Sorensen, K.C.; George, R.D.; Obraztsova, A. SERS substrates fabricated using ceramic filters for the detection of bacteria. Spectrochim Acta A Mol Biomol Spectrosc. 2016, 15, 591-598. [CrossRef] [PubMed]

32. Chen, J.; Wu, X.; Huang, Y.-W.; Zhao, Y. Detection of E. coli using SERS active filters with silver nanorod array. Sensors Actuators B. Chem. 2014, 191, 485-490. [CrossRef]

33. Lin, C.-C.; Yang, Y.-M.; Liao, P.-H.; Chen, D.-W.; Lin, H.-P.; Chang, H.-C. A filter-like AuNPs@MS SERS substrate for Staphylococcus aureus detection. Biosens. Bioelectron. 2013, 53, 519-527. [CrossRef] [PubMed]

34. Hong, J.; Kawashima, A.; Hamada, N. A simple fabrication of plasmonic surface-enhanced Raman scattering (SERS) substrate for pesticide analysis via the immobilization of gold nanoparticles on UF membrane. Appl. Surf. Sci. 2017, 407, 440-446. [CrossRef]

35. Rapid fabrication of silver nanoparticle-coated filter paper as SERS substrate for low-abundance molecules detection. Spectrochim. Acta Part A Mol. Biomol. Spectrosc. 2017, 179, 211-215. [CrossRef] [PubMed]

36. In situ silver nanoparticles synthesis in agarose film supported on filter paper and its application as highly efficient SERS test stripes. Forensic Sci. Int. 2014, 237, e42-e46. [CrossRef] [PubMed]

37. Lin, W.-H.; Lu, Y.-H.; Hsu, Y.-J. Au nanoplates as robust, recyclable SERS substrates for ultrasensitive chemical sensing. J. Colloid Interface Sci. 2014, 418, 87-94. [CrossRef] [PubMed]

38. Honda, M.; Saito, Y.; Smith, N.I.; Fujita, K.; Kawata, S. Nanoscale heating of laser irradiated single gold nanoparticles in liquid. Opt. Express 2011, 19, 12375. [CrossRef] [PubMed]

39. Qin, Z.; Bischof, J.C. Thermophysical and biological responses of gold nanoparticle laser heating. Chem. Soc. Rev. 2012, 41, 1191-1217. [CrossRef] [PubMed]

40. Mochizuki, M.; Asatyas, S.; Suthiwanich, K.; Hayashi, T. Thiol Molecules as Temperature Sensors for Surface-enhanced Raman Scattering Measurements of Heat-sensitive Materials. Chem. Lett. 2016, 45, 1207-1209. [CrossRef] 
41. De Jesús, M.A.; Giesfeldt, K.S.; Sepaniak, M.J. Use of a Sample Translation Technique to Minimize Adverse Effects of Laser Irradiation in Surface-Enhanced Raman Spectrometry. Appl. Spectrosc. 2003, 57, 428-438. [CrossRef] [PubMed]

42. Suh, J.S.; Jeong, D.H.; Lee, M.S. Effect of inhomogeneous broadening on the surface photochemistry of phthalazine. J. Raman Spectrosc. 1999, 30, 595-598. [CrossRef]

43. Song, B. Simple and fast fabrication of superhydrophobic metal wire mesh for efficiently gravity-driven oil/water separation. Mar. Pollut. Bull. 2016. [CrossRef] [PubMed]

44. Yoshida, Y.; Inoue, Y.; Shimosaka, A.; Shirakawa, Y.; Hidaka, J. Effect of aperture structure of Dutch weave mesh on flow resistivity. J. Chem. Eng. Japan 2015. [CrossRef]

45. Lebedev, S.M.; Gefle, O.S.; Amitov, E.T.; Berchuk, D.Y.; Zhuravlev, D.V. Poly(lactic acid)-based polymer composites with high electric and thermal conductivity and their characterization. Polym. Test. 2017, 58, 241-248. [CrossRef]

46. Michota, A.; Bukowska, J. Surface-enhanced Raman scattering (SERS) of 4-mercaptobenzoic acid on silver and gold substrates. J. Raman Spectrosc. 2003, 34, 21-25. [CrossRef]

47. Fang, Y.; Seong, N.-H.; Dlott, D.D. Measurement of the distribution of site enhancements in surface-enhanced Raman scattering. Science 2008, 321, 388-392. [CrossRef] [PubMed]

48. Terekhov, S.N.; Kachan, S.M.; Panarin, A.Y.; Mojzes, P. Surface-enhanced Raman scattering on silvered porous alumina templates: role of multipolar surface plasmon resonant modes. Phys. Chem. Chem. Phys. 2015, 17, 31780-31789. [CrossRef] [PubMed]

49. Petrou, V.; Hill, W. Caries Detection by Diode Laser Raman Spectroscopy. Appl. Spectrosc. 2000, 54, 795-799.

50. Novara, C.; Dalla Marta, S.; Virga, A.; Lamberti, A.; Angelini, A.; Chiadò, A.; Rivolo, P.; Geobaldo, F.; Sergo, V.; Bonifacio, A.; et al. SERS-Active Ag Nanoparticles on Porous Silicon and PDMS Substrates: A Comparative Study of Uniformity and Raman Efficiency. J. Phys. Chem. C 2016, 120, 16946-16953. [CrossRef]

51. Herzog, J.B.; Knight, M.W.; Li, Y.; Evans, K.M.; Halas, N.J.; Natelson, D. Dark Plasmons in Hot Spot Generation and Polarization in Interelectrode Nanoscale Junctions. Nano Lett. 2013, 13, 1359-1364. [CrossRef] [PubMed]

52. Hastings, S.P.; Swanglap, P.; Qian, Z.; Fang, Y.; Park, S.-J.; Link, S.; Engheta, N.; Fakhraai, Z. Quadrupole-Enhanced Raman Scattering. ACS Nano 2014, 8, 9025-9034. [CrossRef] [PubMed]

53. Luna-Pineda, T.; Soto-Feliciano, K.; De La Cruz-Montoya, E.; Pacheco Londoño, L.C.; Ríos-Velázquez, C.; Hernández-Rivera, S.P. Spectroscopic characterization of biological agents using FTIR, normal Raman and surface-enhanced Raman spectroscopies. In Proceedings of the SPIE 6554, Chemical and Biological Sensing VIII, Orlando, FL, USA, 27 April 2007; Fountain III, A.W., Ed.; Volume 6554, p. 65540K.

54. Pearman, W.F.; Lawrence-Snyder, M.; Angel, S.M.; Decho, A.W. Surface-Enhanced Raman Spectroscopy for in Situ Measurements of Signaling Molecules (Autoinducers) Relevant to Bacteria Quorum Sensing. Appl. Spectrosc. 2007, 61, 1295-1300. [CrossRef] [PubMed]

55. Guicheteau, J.; Argue, L.; Emge, D.; Hyre, A.; Jacobson, M.; Christesen, S. Bacillus Spore Classification via Surface-Enhanced Raman Spectroscopy and Principal Component Analysis. Appl. Spectrosc. 2008, 62, 267-272. [CrossRef] [PubMed]

56. Chao, Y.; Zhang, T. Surface-enhanced Raman scattering (SERS) revealing chemical variation during biofilm formation: from initial attachment to mature biofilm. Anal. Bioanal. Chem. 2012, 404, 1465-1475. [CrossRef] [PubMed]

57. Kubryk, P.; Niessner, R.; Ivleva, N.P. The origin of the band at around $730 \mathrm{~cm}^{-1}$ in the SERS spectra of bacteria: a stable isotope approach. Analyst 2016, 141, 2874-2878. [CrossRef] [PubMed]

58. Madzharova, F.; Heiner, Z.; Gühlke, M.; Kneipp, J. Surface-Enhanced Hyper-Raman Spectra of Adenine, Guanine, Cytosine, Thymine, and Uracil. J. Phys. Chem. C 2016, 120, 15415-15423. [CrossRef] [PubMed]

59. Movasaghi, Z.; Rehman, S.; Rehman, I.U. Raman Spectroscopy of Biological Tissues. Appl. Spectrosc. Rev. 2007, 42, 493-541. [CrossRef]

60. Laucks, M.L.; Sengupta, A.; Junge, K.; Davis, E.J.; Swanson, B.D. Comparison of Psychro-Active Arctic Marine Bacteria and Common Mesophillic Bacteria Using Surface-Enhanced Raman Spectroscopy. Appl. Spectrosc. 2005, 59, 1222-1228. [CrossRef] [PubMed]

61. Zhang, J.; Huang, Q.; Yao, G.; Ke, Z.; Zhang, H.; Lu, Y. SERS study of transformation of phenylalanine to tyrosine under particle irradiation. J. Mol. Struct. 2014, 1072, 195-202. [CrossRef] 
62. Krafft, C.; Neudert, L.; Simat, T.; Salzer, R. Near infrared Raman spectra of human brain lipids. Spectrochim. Acta Part A Mol. Biomol. Spectrosc. 2005, 61, 1529-1535. [CrossRef] [PubMed]

63. Dukor, R.K. Vibrational Spectroscopy in the Detection of Cancer. In Handbook of Vibrational Spectroscopy; Griffiths, P.R., Ed.; John Wiley \& Sons, Ltd.: Chichester, UK, 2006; ISBN 9780470027325.

64. Walter, A.; März, A.; Schumacher, W.; Rösch, P.; Popp, J. Towards a fast, high specific and reliable discrimination of bacteria on strain level by means of SERS in a microfluidic device. Lab Chip 2011, 11, 1013. [CrossRef] [PubMed]

65. Demirel, M.C.; Kao, P.; Malvadkar, N.; Wang, H.; Gong, X.; Poss, M.; Allara, D.L. Bio-organism sensing via surface enhanced Raman spectroscopy on controlled metal/polymer nanostructured substrates. Biointerphases 2009, 4, 35-41. [CrossRef] [PubMed]

(C) 2018 by the authors. Licensee MDPI, Basel, Switzerland. This article is an open access article distributed under the terms and conditions of the Creative Commons Attribution (CC BY) license (http:/ / creativecommons.org/licenses/by/4.0/). 